\title{
The Ecology of Pastoralism. Edited by P. Nick Kardulias. 2015. University Press of Colorado, Boulder. 272 pp.
}

\author{
Kārlis Rokpelnis ${ }^{1 *}$ \\ ${ }^{1}$ School of Life and Environmental Sciences, Minzu University of China, Beijing, China. \\ *karlisr@yahoo.com
}

Received October 19, 2015

OPENӘACCESS

Accepted January 8, 2016

DOI 10.14237/ebl.7.1.2016.499

Copyright (C) 2016 Rokpelnis; licensee Society of Ethnobiology. This is an open-access article distributed under the terms of the Creative Commons AttributionNonCommercial 4.0 International Public License (https://creativecommons.org/licenses/by-nc/4.0), which permits non-commercial use, distribution, and reproduction in any medium, provided the original author and source are credited.

One might compare academic and popular writing on pastoralists with that on geishas in Japan. These two groups are routinely described as remnants of the past and are often pitied for the hardship of their daily lives and their livelihoods' spiritual and economic incongruence with modernity. However, these groups capture imaginations and seemingly offer insights into the processes that construct societies through time. Throughout the history of social sciences, pastoralists (broadly referring to people who rely on animal husbandry for a living) have been at the center of a range of heated debates on social arrangements and human use of natural resources. Those debates would most definitely benefit from a more nuanced and clearer understanding of the ways pastoral communities function.

The Ecology of Pastoralism, edited by P. Nick Kardulias and dedicated to the other initial editor, the prematurely deceased Mark T. Shutes, addresses various aspects of the highly flexible and adaptive human-ecosystem interaction cluster that is pastoralism. Time and space are two fundamental challenges for the synthesis of a general theory of pastoralism: debates on the emergence of animal herding out of sedentary farming versus an evolutionary path from gathering to herding are complicated by the fact that herding takes different forms and possibly has had diverging development paths in different parts of the world. Claudia Chang's personal account of her life's work, from archaeology and participant observation of contemporary herding in Greece to studying pastoralists in today's Kazakhstan, elegantly illuminates why we cannot take for granted that the motivations and actions of pastoralists have remained constant through time and space.
As Chang demonstrates, the reinterpretation and adaptation of past identities to today's circumstances in Central Asia is highly ideological, both politically and intellectually, which creates further hurdles to a unified interpretation of pastoralism in space. The same applies to historical experience, as Erik G. Johannesson shows in his discussion of mortuary practices in Late Bronze and Early Iron Age Mongolia, where pastoralism carried a particular symbolic weight that, according to the author, far exceeded its livelihood role. Michelle Negus Cleary provides counterarguments to a different kind of exaggeration - that of the strict separation and enmity between steppe pastoralists and settled oasis dwellers in late Iron Age Central Asia. Using analysis of fortification typologies, Negus Cleary maintains that at various times pastoralists as well as agriculturalists would use the same fortifications, and thus settling down behind walls might as well be yet another expression of pastoralist adaptation. In the case of Navajo herders, Lawrence A. Kuznar presents a more conventional route of adaptation away from agricultural settlement towards pastoralism driven by encroaching colonial interests and amplified by emergent global market forces.

Similar colonial and post-colonial adaptations among FulBe pastoralists in the Chad Basin are described by Mark Moritz, who calls for a nuanced understanding of the neo-patrimonial state government in which individuals in governmental agencies (rather than an abstract state) make decisions that the pastoralists have to reckon with. Moritz argues that pastoralists seek integration into the patrimonial networks that permeate the state in order to ensure access to rangeland. The case for a careful adaptation 
and flexibility-focused understanding of pastoralism is further strengthened with examples of Hunza vertical transhumance in Pakistan presented by Homayun Sidky and Kardulias' description of island pastoralists in Greece.

Nikolay N. Kradin argues that flexible species assortments and opportunistic grazing approaches historically allowed for the formation of the amorphous hierarchies that could mount challenges to the strongest agricultural empires and then vanish seemingly overnight. Mark T. Shutes complements this notion by demonstrating that adaptations through animal husbandry continue to play a crucial role in community and individual identities in increasingly industrialized rural economies. Shutes' discussions of farmers' adaptation to new realities in Ireland show how transnational regulation and subsidy systems become additional, hardly predictable, factors to be added to the bundle of uncertainties that herd owners face as individuals who must maintain status and a community role.

A world-systems analysis comes closest to serving as a unified theoretical framework for the volume. It seems that pastoralists' ability to derive value and livelihood from lands unsuitable, or to borrow from James Scott, unreadable to the state, serves well for collective and individual responses to marginalization and resource extraction. Thomas D.
Hall synthesizes the chapters in this volume into a case for an understanding that living with herds, among other forms of adaptation and social organization, "can only be explained when embedded in a larger, inter-societal context" (p. 275; emphasis in the original).

Such a conclusion will hardly satisfy a reader looking for rules of thumb in understanding pastoralists today or in the past. But it truthfully reflects the confusing complexity researchers of pastoralists encounter on a daily basis. With no hint of idyllic musings, the volume brings the reader well beyond facile generalizations of pastoral life or any equivalent geisha romanticizing. Those with a keen eye for ecological nuance, particularly detailed environmental indicators and ecosystem measurements, might call foul on using 'ecology' in the title since the focus of the volume is societal. The relatively limited attention paid to climate change comes as a surprise but can be understood as an editorial choice to pick a focus and stick with it. The omission of equilibrium versus nonequilibrium debate, however, significantly dents the ecological credibility and usefulness of the volume. Regardless of this shortcoming, The Ecology of Pastoralism brings out nuances and at times can be a captivating read for anyone who enjoys piecing together complex puzzles. 